\title{
The Effect of Counterions in Hydrophobic Ion pairs on Oral
}

\section{Bioavailability of Exenatide}

\section{Thi Nhu Quynh Phan a,b*, Ruba Ismail c,d*, Bao Le-Vinh ${ }^{a, e}$, Sergey Zaichik a, Flavia}

Laffleur a $^{\text {, Andreas Bernkop-Schnürch a,*** }}$

a Department of Pharmaceutical Technology, Institute of Pharmacy, University of Innsbruck, Innsbruck, Austria

${ }^{b}$ Faculty of Pharmacy, University of Medicine and Pharmacy, Hue University, Thua Thien Hue, Viet Nam

c Institute of Pharmaceutical Technology and Regulatory Affairs, Institute of Pharmacy, University of Szeged, Eötvös u. 6, H-6720 Szeged, Hungary

d Institute of Pharmaceutical Technology and Regulatory Affairs, Interdisciplinary Centre of Excellence, University of Szeged, Eötvös u. 6, H-6720 Szeged, Hungary

e Department of Industrial Pharmacy, Faculty of Pharmacy, University of Medicine and Pharmacy at Ho Chi Minh City, Ho Chi Minh City, Viet Nam

\section{* First authors}

**Corresponding author: Center for Chemistry and Biomedicine, Department of Pharmaceutical Technology, Institute of Pharmacy, University of Innsbruck, Innrain 80/82, 6020 Innsbruck, Austria. E-mail address: andreas.bernkop@uibk.ac.at. 


\section{Suppporting Information}

Table S1: Information about the excipients used in SEDDS

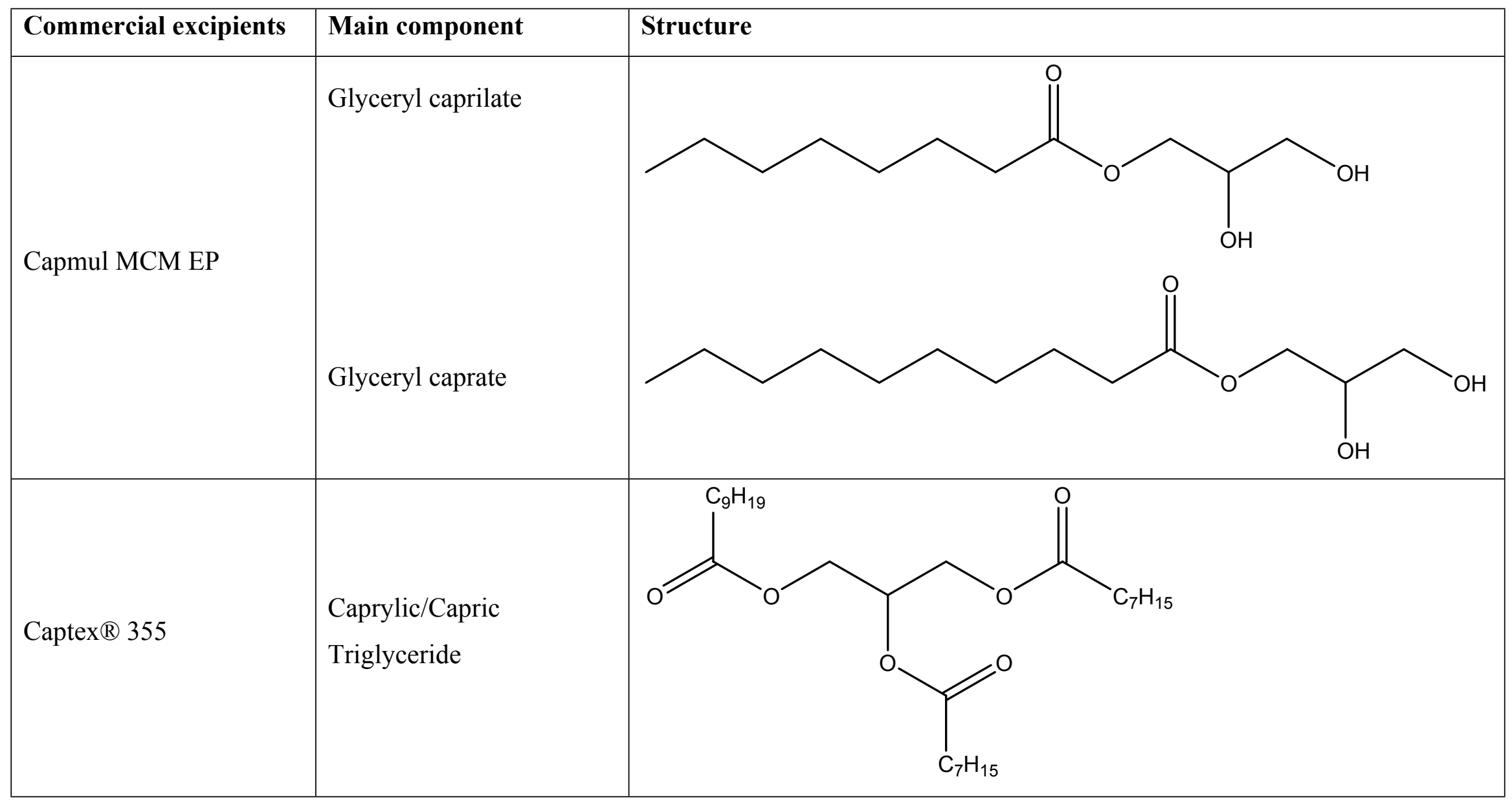


Table S1: Information about the excipients used in SEDDS (cont.)

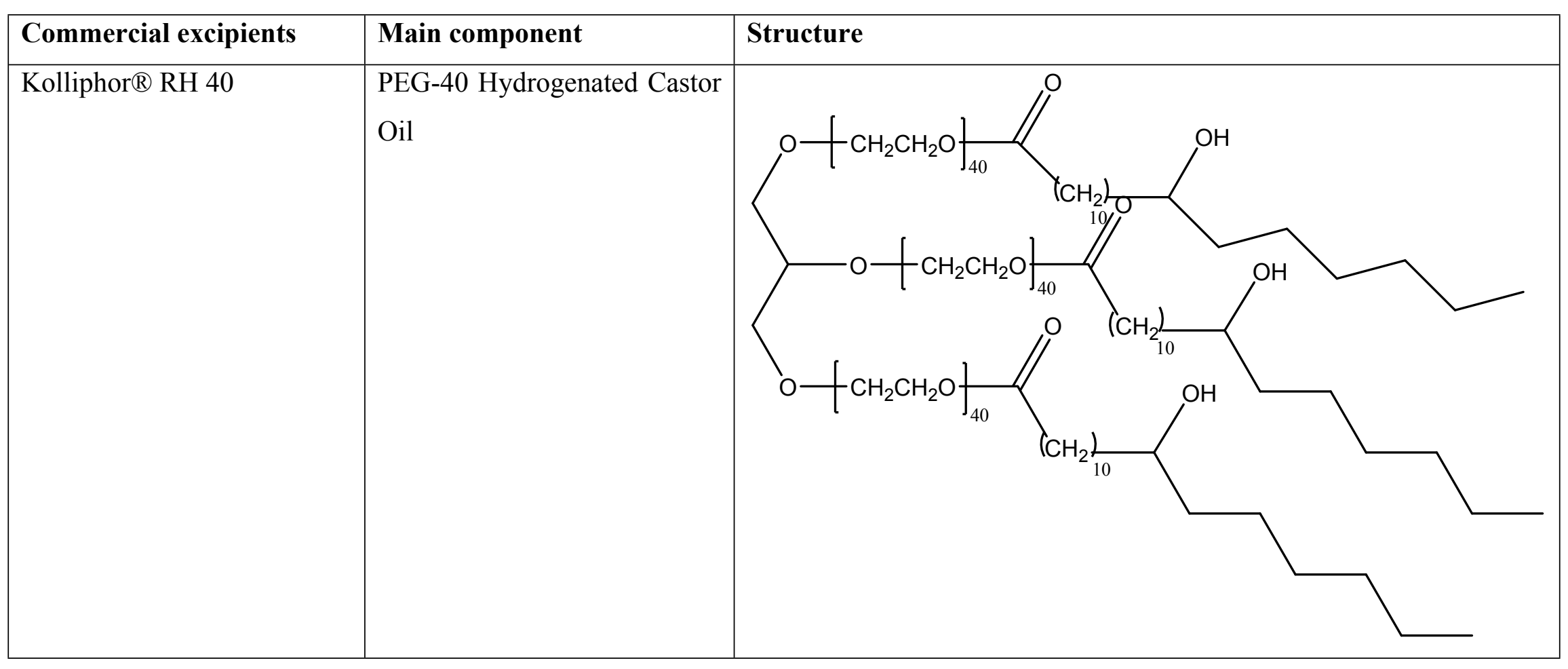

